\title{
Carrizo Abierto: procesos escénicos para la recuperación de la tradición oral comcaac
}

\author{
Alma Cristina Vázquez Bátriz*
}

\section{Descripción del proyecto}

Es así como aunado al lenguaje escénico trabajado desde hace dos años por Colectivo Sonder, que este proyecto surge como un laboratorio experimental de artes escénicas para jóvenes de la comunidad de Punta Chueca.

\section{Objetivos}

- Propiciar un espacio de creación, acompañamiento y capacitación en el que las prácticas tradicionales, saberes y costumbres de la nación comcaac dialogarán con lenguajes artísticos contemporáneos.

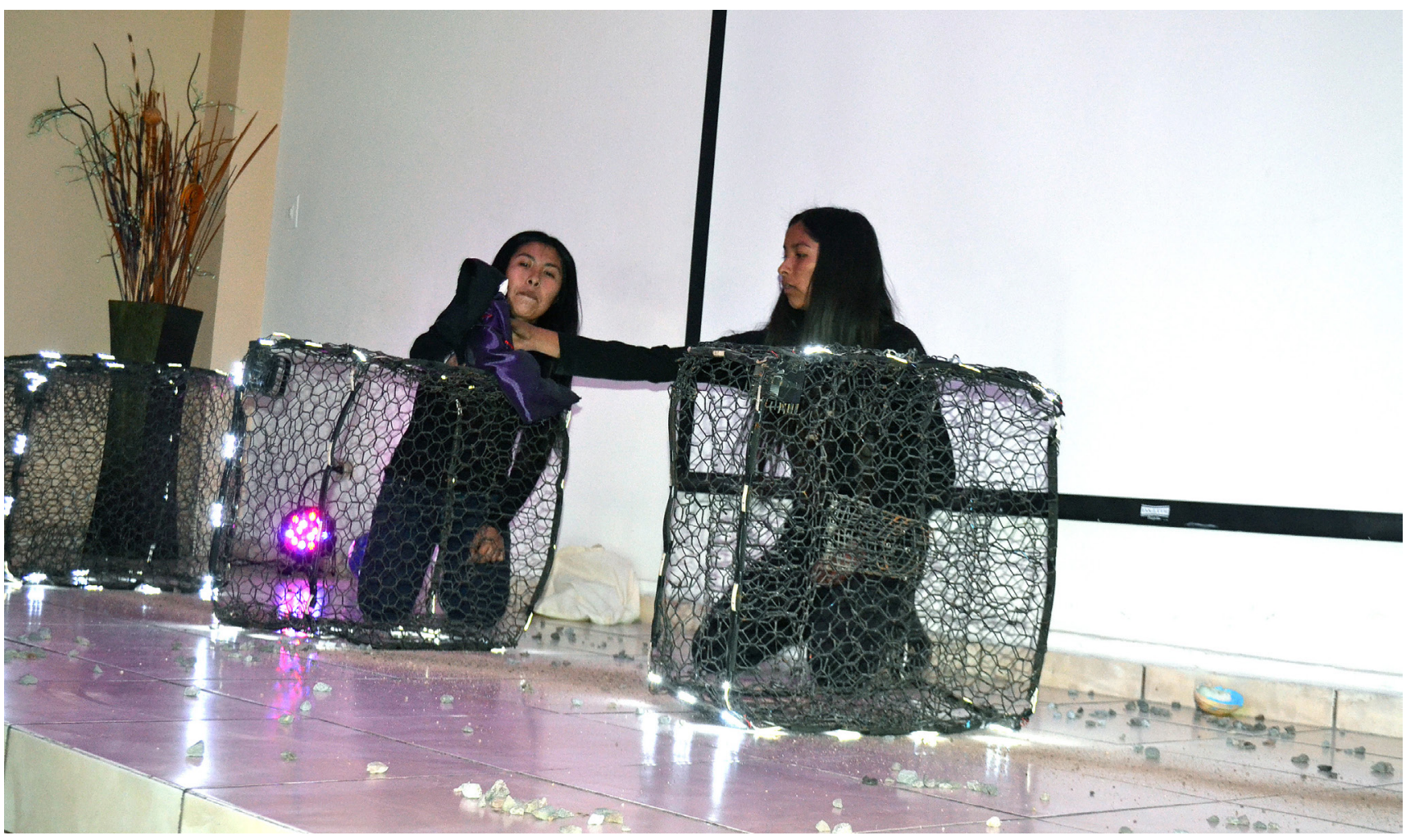

*Actriz formada en la Universidad Autónoma de Chihuahua (UACH), gestora cultural por la Universidad de Guadalajara, coordinadora del proyecto Carrizo Abierto: laboratorio escénico para jóvenes comcaac 2017 y miembro de Colectivo Sonder, actualmente colabora como titiritera en la compañía L'ormiga Títeres en Hermosillo, Sonora.

\section{Savî́a}


- Posibilitar el surgimiento de nuevas formas de apropiación y de difusión del patrimonio cultural intangible de dicha comunidad.

Se tiene como meta la creación de un montaje escénico/expositivo que girara alrededor del mito de la Mujer Azul (la mujer pintada) perteneciente a su tradición oral.

Mito: el primer seri fue una mujer llamada Primer Mujer o Mujer Pintada. Su cuerpo y su cara estaban pintados de azul para verse más bella y se hablaba de ella como "la mujer que es bella". Ella salió del carrizo y atravesó la isla del tiburón hasta un lugar en que encontró a un hombre. Se casaron y tuvieron hijos. A pesar de ser hermanos, se casaron.
El viejo, el venado y el coyote. Estética y cosmogonía

Miguel Olmos Aguilera

La realización del laboratorio escénico en la comunidad de Punta Chueca, se compuso por cuatro módulos donde se compartieron herramientas escénicas para la expresión dramática, liberación de la imaginación, el cuerpo, así como la investigación de su tradición oral. Se busca generar entre toda una base metodológica que dejará un sustento, una continuidad del trabajo y un resultado final.

\section{Los módulos}

Taller de juegos recreativos

En este taller involucramos juegos tradicionales de la comunidad comcaac y otros juegos propuesto por el

\section{Darlen y Tina Romero Torres presentan sus costumbres cotidianas en la comunidad comcaac}

Como resultado de un taller práctico de teatro en la comunidad comcaac y una investigación sobre sus costumbres surgió la puesta en escena Territorio, en la que las hermanas Darlen y Tina Romero Torres muestran la práctica de su cultura.

Fue en el auditorio del Departamento de Trabajo Social donde se presentó la obra de teatro Territorio. Cuando memoria y presente buscan ser uno, como parte de las actividades preparadas con motivo de la reciente conmemoración del Día Internacional de la Mujer.

Darlen y Tina, sin muchos elementos teatrales, pero sí con algunos sumamente representativos de la cultura seri, expusieron y transmitieron algunos conceptos y características del lugar, de la gente, del significado de los detalles, de la vida comcaac, a los asistentes, quienes estuvieron pendientes de todos y cada uno de los movimientos de las protagonistas.

En la obra, las jóvenes intérpretes, fueron bondadosas como su gente, alegres como sus bailes, luminosas como el entorno y disciplinadas como cada una de las ceremonias y creencias.

Cristina Vázquez Bátriz, integrante del Colectivo Sonder, comentó que esta obra de teatro fue producto del proyecto Carrizo Abierto, un laboratorio con diferentes talleres que desarrollaron en la comunidad para conocer y rescatar información para compartirla a través de ciertos productos, como fue esta obra de teatro.

"En el laboratorio se impartieron diferentes talleres y en cada taller se buscaba obtener información para incluirla en la obra. Fue en el taller de teatro de la memoria donde se obtuvo información acerca de la problemática de la comunidad y también, acerca de todo aquello

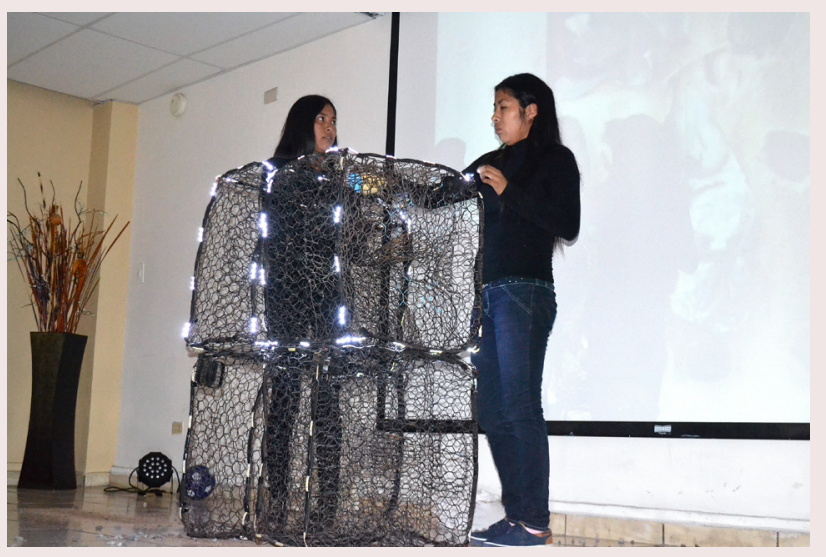

que es un obstáculo para que la transmisión de la información vaya de los abuelos a las nuevas generaciones", explicó.

Dijo que esa situación se torna difícil, pues por lo general tienen que hacer algún tipo de trueque para que los adultos, los abuelos, los viejos, quieran compartir su conocimiento y transmitirlo a las nuevas generaciones.

"Esto no es una historia como un teatro convencional, es solo un montaje en donde se expresan las ideas que ellas quieren comunicar", añadió; y dijo que Sonder ha venido trabajando desde hace tres años en otros proyectos con los integrantes de la etnia.

Comentó que esta es la tercera ocasión que se presenta la obra: la primera fue en el Museo de Culturas Populares, en noviembre de 2017; la segunda, en el Festival Alfonso Ortiz Tirado, en Álamos, Sonora, en enero de este año; y ahora, la tercera ocasión, en el Departamento de Trabajo Social de la Universidad de Sonora. 
